\title{
Xanthohumol induces paraptosis of leukemia cells through p38 mitogen activated protein kinase signaling pathway
}

\author{
Xiangquan Mir, ${ }^{1,2}$ Chunming Wang ${ }^{1}$, Chao Sun $^{3}, X$ Xu Chen ${ }^{1}$, Xiang Huo ${ }^{1}$, Yiming \\ Zhang ${ }^{2}$, Gang Li ${ }^{2}$, Bo Xu ${ }^{2}$, Jun Zhang ${ }^{4}$, Jianxin Xie ${ }^{4}$, Zhenhua Wang ${ }^{2}$, Ji $\mathbf{L i}^{2}$ \\ ${ }^{1}$ School of Life Sciences, Lanzhou University, Lanzhou, Gansu 730000, P.R. China \\ ${ }^{2}$ Center for Mitochondrial and Healthy Aging, College of Life Sciences, Yantai University, Yantai, Shandong 264005, P.R. China \\ ${ }^{3}$ Institute of Modern Physics, Chinese Academy of Sciences, Lanzhou 730000, P.R. China \\ ${ }^{4}$ Shihezi University School of Medicine, Shihezi, Xinjiang 832000, P.R. China
}

Correspondence to: Ji Li, email: lijimelissafang@yahoo.com

Keywords: xanthohumol, paraptosis, p38-MAPK, cytoplasmic vacuolation, ER stress

Received: November 22, $2016 \quad$ Accepted: March 06, 2017

Published: March 14, 2017

Copyright: Mi et al. This is an open-access article distributed under the terms of the Creative Commons Attribution License (CC-BY), which permits unrestricted use, distribution, and reproduction in any medium, provided the original author and source are credited.

\section{ABSTRACT}

Xanthohumol as a natural polyphenol demonstrates an anticancer activity, but its underlying mechanism remains unclear. In this study, we showed that xanthohumol (XN) induces paraptosis of leukemia cells. The paraptosis is one cell death which is characterized by dilation of the endoplasmic reticulum and/or mitochondria. The results demonstrated that XN treatment significantly inhibited cell proliferation and triggered extensive cytoplasmic vacuolation of HL-60 leukemia cells, but it did not cause the cleavage of caspase- 3 protein or apoptosis. In contrast, $\mathbf{X N}$ treatment resulted in LC3-II accumulation through blocking of autophagosome maturation. Interestingly, the induction of cytoplasmic vacuolization by $\mathrm{XN}$ is not associated with autophagy modulated by XN, therefore, XN-induced cell death of HL-60 leukemia cells is not the classical apoptotic cell death. Intriguingly, $\mathrm{XN}$ treatment triggered the dilatation of endoplasma reticulum (ER) and induced ER stress by upregulating C/EBP homologous protein and unfolded protein response regulator Grp78/Bip. Furthermore, XN treatment triggered p38 mitogen activated protein kinase and its specific inhibitor inhibited the paraptosis of HL-60 leukemia cells by XN. In conclusion, we for the first time demonstrated that XN treatment can induce paraptosis of leukemia cells through activation of p38 MAPK signaling.

\section{INTRODUCTION}

The chemotherapeutic agents mostly demonstrate anti-cancer activity through caspase-dependent apoptosis [1]. The chemotherapy resistance for cancer cells is a limited factor for the success of antitumor drugs in cancer treatment. These could be due to genetic mutations in the pro-apoptotic protein of Bax and augment of anti-apoptotic proteins of $\mathrm{Bcl}-2$ and $\mathrm{X}$-chromosome linked inhibitor of apoptosis [2, 3]. Therefore, the therapies according to triggering non-apoptotic cell death could provide a good approach for treatment of cancers that are resistant to multi-drugs-induced apoptosis [4].

Paraptosis is characterized by cytoplasmic vacuolation that could be generated from swelling of the endoplasmic reticulum and/or mitochondria. The paraptosis usually does not have caspase activation an apoptotic hallmark [5, 6]. Moreover, there is evidence that a protein synthesis inhibitor cycloheximide (CHX) can block the formation of cytoplasmic vacuole in cytoplasmic vacuolation-mediated cell death and paraptosis [6, 7]. A previous report showed that autophagic marker LC3-II are upregulated and the endoplasmic reticulum stress markers unfolded protein response regulator Grp78/Bip and transcription factor $\mathrm{CHOP}$ are observed in paraptosis of cancer cells [5]. In contrast, regarding whether a paraptosis process is involved in cell death of leukemia cells and dopaminergic neuroblastoma cells have not been elucidated [8]. Several natural products such as curcumin, celastrol, ophiobolin A and paclitaxel have demonstrated anti-cancer activities through the induction of paraptosisrelated cell death, but there is no study to show the direct antitumor effects of Xanthohumol (XN) via paraptosis.

Hops (Humulus lupulus L.) flowers have been used as a raw material in the industry to generate aroma and flavor. Besides the application of hops in the 
industry, they have been also used for different medical purposes. Xanthohumol is an important flavonoid in hops. Xanthohumol (XN) (Figure 1A) is a prenylated chalcone that was isolated from the female hop plant, Humulus lupulus, possesses proven pharmacologic safety and multiple bioactivities, including anti-cancer, anti-diabetes, anti-inflammatory and anti-bacteria [9]. In current study, we demonstrated that $\mathrm{XN}$ induces paraptosis of HL-60 leukemia cells, and the paraptosis occurred in HL-60 cells is characterized with cytoplasmic vacuolation and dilated endoplasmic reticulum triggering endoplasmic reticulum (ER) stress. In addition, our results revealed that p38 MAPK plays a critical role in the $\mathrm{XN}$-induced paraptosis. Therefore, the paraptosis of leukemia cells induced by Xanthohumol could be an implication of Xanthohumol for cancer therapeutics.

\section{RESULTS}

\section{XN inhibits proliferation and induces cytoplasmic vacuolation}

In order to investigate the anti-malignant tumor effects of XN, HL-60 leukemia cells were treated with Xanthohumol (approximately $0-50 \mu \mathrm{M}$ ) for 48 hours and cell viability assays were performed using Trypan blue assay; besides leukemia cells, the SH-SY5Y neuroblastoma cells were also tested the response to XN treatment, SH-SY5Y neuroblastoma cells were administrated with $\mathrm{XN}$ for $48 \mathrm{~h}$ and cell viability assays were performed by CCK 8 assay, respectively. It was observed that XN dose-dependently decreased cell viability of both HL-60 leukemia cells and SH-SY5Y neuroblastoma cells (Figure 1B), suggesting a general cytotoxic effect of XN on cancer cells. Microscopic observation revealed that stimulation with higher XN concentrations (more than $50 \mu \mathrm{M}$ ) led to cell detachment. Treatment with XN induced extensive cytoplasmic vacuolation in HL-60 leukemia cells and SH-SY5Y neuroblastoma cells (Figure 1C), and the number of vacuolated cells was dose-dependently increased (Figure 1D). Compared with the SH-SY5Y neuroblastoma cells, the HL-60 leukemia cells displayed more sensitive to XN treatment, therefore, HL-60 leukemia cells are used for further determination of mechanisms by which XN induces paratosis of cancer cells.

\section{Apoptosis and autophagy are not involved in $\mathrm{XN}$-induced cell death}

The results demonstrated that $\mathrm{XN}$ treatment induced cell death accompanying with cytoplasmic vacuolation that could a new type of cell death caused by XN. As in most literature reported, cell death induced by $\mathrm{XN}$ is attributed to apoptosis [10, 11]. Firstly, in order to examine caspase activation, HL-60 leukemia cells were administrated with $5 \mu \mathrm{M}, 10 \mu \mathrm{M}$, and $15 \mu \mathrm{M}$ of $\mathrm{XN}$ for $48 \mathrm{~h}$, respectively, and the levels of caspase- 3 were determined. When the cells were treated with $\mathrm{XN}$, the full length of caspase- 3 were not altered, and the cleaved fragments of caspase-3 were not identified (Figure 2A). Next, to further prove $\mathrm{XN}$-treated cells did not induce apoptosis, we carried out flow cytometry analysis showed that $\mathrm{XN}$ did not significantly augmented the number of apoptotic cells (Figure 2B). The HL-60 leukemia cells were administrated with a caspase inhibitor $\mathrm{z}$-VAD-fmk, prior to the treatment of $\mathrm{XN}$, the number of viable cells and the cells with vacuolation (Figure $2 \mathrm{C}$ and $2 \mathrm{D}$ ) was not changed obviously. Taken together, these results indicated that apoptosis might not contribute to the cytotoxicity of $\mathrm{XN}$ toward HL-60 cells. However, the HL-60 cells with $\mathrm{XN}$ treatment caused extensive cytoplasmic vacuolation, therefore, we further assessed whether $\mathrm{XN}$-induced vacuolation and cell death were related to autophagic cell death. Firstly, we measured autophagy induction with the fluorescence microscopy and using Cyto-ID ${ }^{\circledR}$ Green as a specific autophagy dye that does not stains lysosomes but can stain autophagosomes in the HL-60 leukemia cells, emitting green flurorescence and forming punctate structures. It clearly showed that there was no Cyto-ID fluorescence was detected in the control group, but HL60 leukemia cells treated with $15 \mu \mathrm{M}$ of $\mathrm{XN}$ for $48 \mathrm{~h}$ increased the level of Cyto-ID signal (green fluorescence) (Figure 3A). The increase in green fluorescence could be related with phosphatidylethanolamine (PE) conjugation. The augmented formation of autophagosomes could be a reason, another reason is the impaired maturation of autophagosomes-induced block of LC3-II degradation. In order to distinguish the difference of the two possibilities, we tested the protein expression levels of Beclin-1, LC3II and p62. There is evidence that Beclin-1 as a critical protein mediating the activation of autophagy and the Beclin-1 has a short BH3 motif to interact with Bcl-2. When the HL-60 leukemia cells were administrated with $5 \mu \mathrm{M}, 10 \mu \mathrm{M}$ and $15 \mu \mathrm{M}$ of $\mathrm{XN}$ for $48 \mathrm{~h}$, respectively, the increased expression levels of LC3-II and p62 but not Beclin-1 were found (Figure 3B). These results suggested that $\mathrm{XN}$ treatment-induced the up-regulated LC3-II expression could be an attenuation of autophagosome maturation. However, we found that the HL-60 leukemia cells were pre-administrated with the inhibitors of autophagy, 3-MA or bafilomycin A1 did not have any effects on $\mathrm{XN}$ induced cell death (Figure $3 \mathrm{C}$ ) and $\mathrm{XN}$ induced cellular vacuolation (Figure 3D). Taken together, these results strongly indicated that the apoptotic or autophagic cell death pathway is not involved in the $\mathrm{XN}$-induced cytoplasmic vacuolation mediated HL-60 leukemia cell death. 


\section{Paratosis is occurred with $\mathrm{XN}$ treatment of HL-60 leukemia cell}

$\mathrm{XN}$ treatment caused paraptosis of vacuolation without induction of caspase activation and autophagic flux (Figures 2 and 3). Because cytoplasmic vacuolation have been shown to be associated with paraptosis with dilatation of endoplasmic reticulum that induces ER stress [12, 13]. Cytoplasmic vacuoles initiated forming after $6 \mathrm{~h}$ of $\mathrm{XN}$ treatment and peaked at about $48 \mathrm{~h}$ in HL-60 leukemia cells. The intracellular vacuoles were enlarged gradually and the nuclei of XN treated cells were located peripherally and the $\mathrm{XN}$ treatment did not trigger fragmentation or chromatin condensation of the nuclei in HL-60 cells. In order to characterize the process of vacuolar formation, a transmission electron microscopy (TEM) was used to analysis of HL-60 leukemia cells at $6 \mathrm{~h}$ or $48 \mathrm{~h}$ after treatment with $15 \mu \mathrm{M}$ of XN. Compared to the untreated cells, cells incubated with $\mathrm{XN}$ for $6 \mathrm{~h}$ showed that cytoplasmic vacuoles look like be fused and the swollen ER cisternae occurred in the HL-60 cells. The leukemia cells were incubated with $\mathrm{XN}$ for $48 \mathrm{~h}$ demonstrated one large and massive smaller cytoplasmic vacuoles. The vacuoles were lacked of visible cytoplasmic organelle, it indicated that XN treatmentinduced cytoplasmic vacuoles were derived from the dilated endoplasmic reticulum (ER) cisternae in the HL-60 leukemia cells (Figure 4A). Cells were incubated with XN for 12 or 24 hours, then washed and maintained in $\mathrm{XN}$-free medium for another 36 or 24 hours. Intriguingly, there were no vacuolated cells visible after removing $\mathrm{XN}$ and further incubated with $\mathrm{XN}$-free culture medium, and the trypan blue assay was employed to analyze the viable cells after XNtreatment and removal of $\mathrm{XN}$ at different times (Figure 4B). The result suggested that the cytoplasmic vacuolation was reversible but it lead to irreversible cell injury. Then the protein expression levels of the ER stress markers, CHOP and Bip/Grp78 caused by XN treatment were determined in HL-60 leukemia cells. Treatment with $5 \mu \mathrm{M}, 10 \mu \mathrm{M}$, and $15 \mu \mathrm{M}$ XN for $48 \mathrm{~h}$ significantly increased the protein levels of CHOP and Bip/Grp78 in HL-60 leukemia cells (Figure 4C). Recently, other investigators reported that the proteasome dysfunction is required for the dilation of mitochondria/endoplasmic reticulum [14]. Thus, we asked whether $\mathrm{XN}$ treatment also impairs proteasome activity in HL-60 leukemia cells. We found that XN-treated cells significantly inhibited proteasome activity (Figure 4D) and accumulated poly-ubquitinated proteins (Figure 4E). Therefore, the results indicate that $\mathrm{XN}$-induced death of HL60 leukemia cells under certain dose and time conditions was paraptosis. The paraptosis needs novo protein synthesis [15], then we further determined whether a new protein synthesis is involved in the XN induced-paraptosis. The HL-60 leukemia cells were administrated with the protein synthesis inhibitor, cycloheximide (CHX) that attenuated cell death in the XN treated HL-60 leukemia cells (Figure 4F).
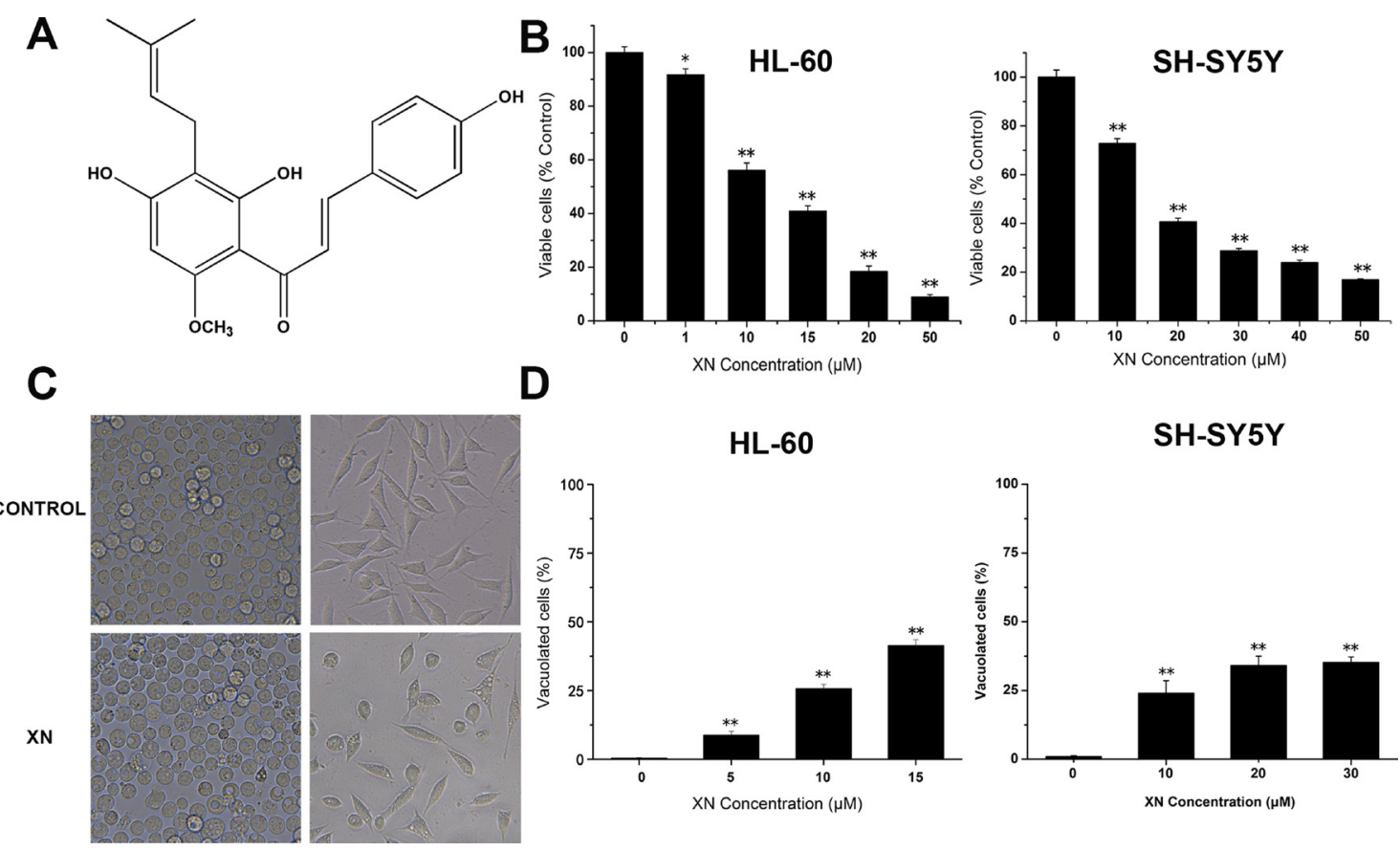

D
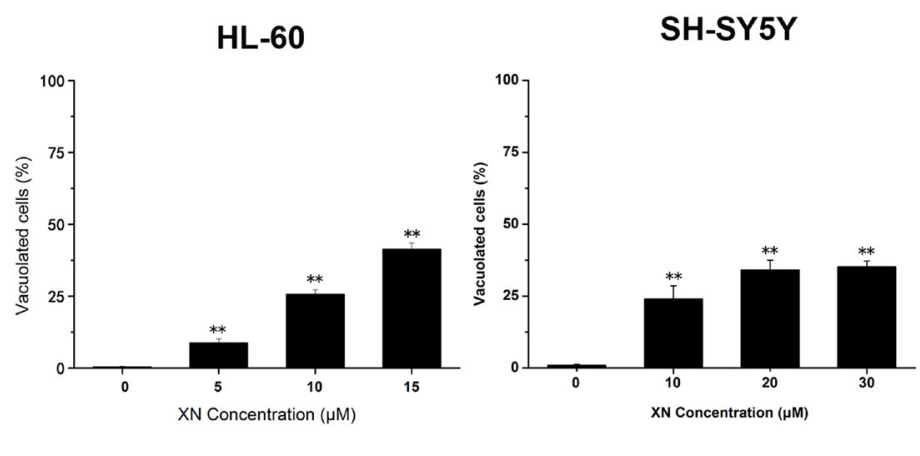

Figure 1: XN treatment results in reduced cell viability and morphological changes in cancer cells. (A) The chemical structure of xanthohumol (XN). (B) HL-60 leukemia cells and SH-SY5Y neuroblastoma cells were treated for $48 \mathrm{~h}$ with various concentrations of XN $(1-50 \mu \mathrm{M})$. The cell viability of HL-60 cells was measured by trypan blue staining and the cell viability of SH-SY5Y cells was assessed using CCK-8 assay. (C) The cells were treated with XN at $15 \mu \mathrm{M}$ for $48 \mathrm{~h}$, and morphology was examined using light microscope. (D) The cells were treated with different concentrations of XN for $48 \mathrm{~h}$, and the percentage of vacuolated cells was measured using light microscope. All data are presented as mean \pm S.D. from three independent experiments. ${ }^{*} P<0.05, * * P<0.01$ vs. control. 
A

Pro- Caspase-3

Cleaved Caspase-

$\beta$-actin
B

$\bar{\alpha}$

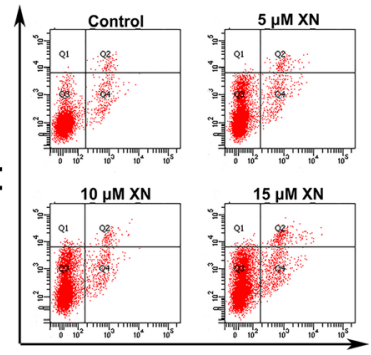

Annexin V-FITC
C

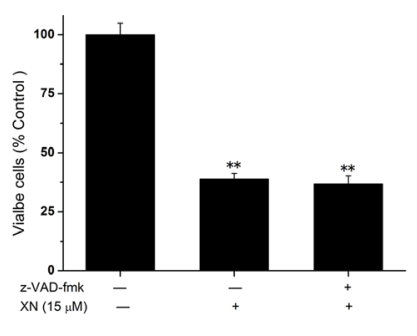

D

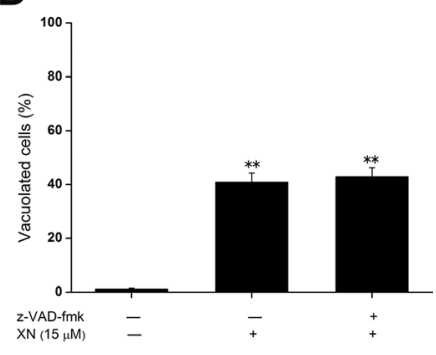

Figure 2: Apoptosis is not involved in the $\mathrm{XN}$-induced cell death. (A) The HL-60 leukemia cells were treated with 5, 10, 15 $\mu \mathrm{M}$ $\mathrm{XN}$ for $48 \mathrm{~h}$, and caspase-3 protein levels were measured. (B) The cells were analyzed for effects of XN on apoptosis by Annexin V-FITC/PI staining, and fluorescence was analyzed using flow cytometry. (C and D) HL-60 cells were pretreated with z-VAD-fmk at $50 \mu \mathrm{M}$ for $1 \mathrm{~h}$ before treatment of XN at $15 \mu \mathrm{M}$ for $48 \mathrm{~h}$. The percentage of viable cells (C) and vacuolated cells (D) were also measured. All data are expressed as mean \pm S.D. from three independent experiments. $* * P<0.01 v s$. control group.
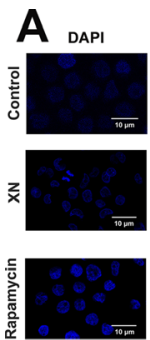
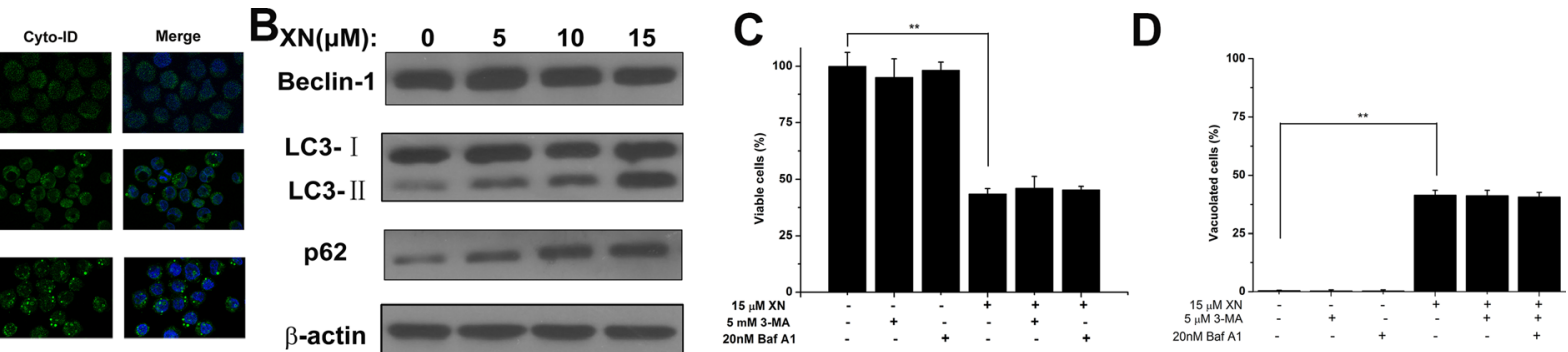

Figure 3: XN treatment alters autophagic influx. (A) The HL-60 leukemia cells were treated with $15 \mu \mathrm{M}$ XN for $48 \mathrm{~h}$. The cells were then loaded with Cyto-ID for $30 \mathrm{~min}$ and immediately imaged by confocal microscopy. The cells were treated with $200 \mathrm{nM}$ rapamycin overnight as positive control of autophagy. (B) The cells were treated with 5, 10, $15 \mu \mathrm{M} \mathrm{XN}$ for $48 \mathrm{~h}$ and immunoblotting was used to determine protein levels of Beclin-1,LC3-II and p62. b-actin was used as a loading control. (C and D) The cells were treated with 3-MA $(5 \mathrm{mM}, 1 \mathrm{~h})$ and bafilomycin- A1 $(20 \mathrm{nM}, 1 \mathrm{~h})$ prior to treatment of $\mathrm{XN}$ at $15 \mu \mathrm{M}$ for $48 \mathrm{~h}$. The percentages of viable cells $(\mathrm{C})$ and vacuolated cells (D) were measured. Data are expressed as mean \pm S.D. from three independent experiments. $* * P<0.01 v s$. control group.

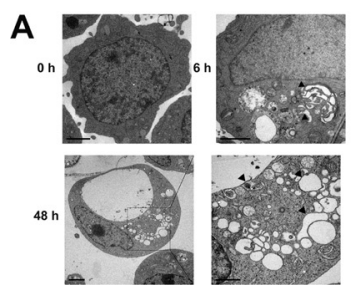

D

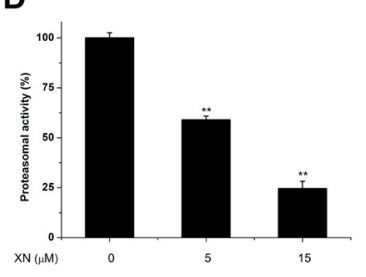

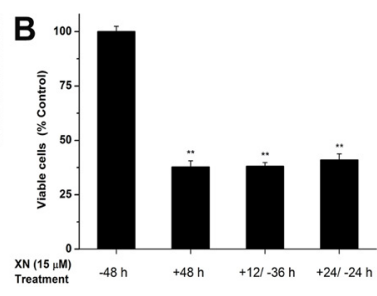

C

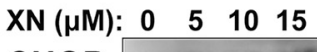

CHOP

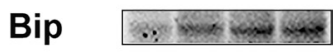

$\beta$ - actin

$\mathbf{E}$

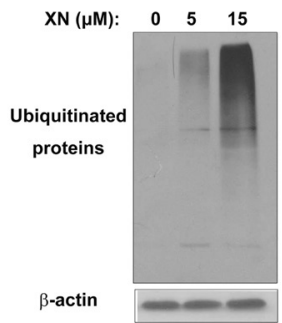

Figure 4: XN induces paraptosis of HL-60 leukemia cells. (A) The cells were treated with $15 \mu \mathrm{M} X \mathrm{~N}$ for the indicated time points and observed by transmission electron microscopy. Arrows indicate the normal ER in control cells and arrowheads indicate dilation of ER. Bars, $2 \mu \mathrm{m}$. (B) Decreased cell viability of HL-60 cells with either continuous presence of drug for $48 \mathrm{~h}$ or treated with drug for $12 \mathrm{~h}$ or $24 \mathrm{~h}$ and shifted to normal medium for remaining periods $(+12 /-36 \mathrm{~h},+24 /-24 \mathrm{~h})$. (C) Western blot was used to determine protein levels of CHOP and Bip in cells treated with $5 \mu \mathrm{M}, 10 \mu \mathrm{M}, 15 \mu \mathrm{M} \mathrm{XN}$ for $48 \mathrm{~h}$. (D and E) The cells were treated with $5 \mu \mathrm{M}, 15 \mu \mathrm{M}$ XN for $48 \mathrm{~h}$, followed by measuring inhibition of the proteasomal activity using proteasome activity assay kit and Western blotting analysis using specific antibodies to ubiquitin (D). (E) The cells were pretreated with CHX (20 $\mu \mathrm{M})$, after which cells were treated with $15 \mu \mathrm{M}$ XN for $48 \mathrm{~h}$. The percentage of viable cells was measured. All data are expressed as mean \pm S.D. from three independent experiments. $* P<0.01 v s$. control group. 


\section{p38 mitogen activated protein kinase mediates paraptosis by $\mathrm{XN}$}

In order to elucidate the signaling mechanisms by which XN treatment induced paraptosis in the HL-60 leukemia cells, we monitored the phosphorylation of p38 mitogen activated protein kinase (MAPK) by immunoblotting. The immunoblotting results showed that p38 MAPK was progressively activated but extracellular signal-regulated kinase (ERK) did not alter (Figure 5A). The importance of these MAPK signals were characterized by their specific inhibitors respectively, we found that $\mathrm{XN}$-induced cell death of HL-60 leukemia cells was significantly inhibited by p38 MAPK inhibitor SB203580 (Figure 5B). Overall, these results demonstrated that XNinduced cell death of HL-60 leukemia cells is paraptosis that was characterized by cytoplasmic vacuolation without caspase activation and autophagic influx. The dilated endoplasmic reticulum and up-regulation of ER stress markers in HL-60 leukemia were also the characteristics of $\mathrm{XN}$-induced cell death. The p38 MAPK triggered by $\mathrm{XN}$ treatment may play a crucial role in the $\mathrm{XN}$ inducedparaptosis.

\section{DISCUSSION}

The elimination of malignant cancer cells usually depends on apoptotic pathways. There are more evidence noted that some of non-apoptotic pathways may contribute to tumor cell death induced by anti-cancer drugs. The caspase activation plays a critical role in apoptosis and the apoptosis is characterized with morphological and biochemical features such as chromatin fragmentation and alterations in apoptotic proteins $[3,16]$. The paraptosis is not apoptotic cell death and the physiological roles and molecular pathways that involved in the paraptosis are not completely understood [17]. There are more evidence that as compared to normal cells, tumor cells usually demonstrate higher levels of endoplasmic reticulum (ER) stress $[18,19]$. Thus, induction of paraptosis that targets mitochondria/endoplasmic reticulum (ER), could offer an attractive approach to kill cancer cells with resistance to the conventional pro-apoptotic chemotherapies.

The mechanisms by which XN exerts its anticancer activity include the chemo-preventive activity through attenuation of the development of carcinogenesis [20] reduction of proliferation, apoptosis inhibition [21] and block of migration [22], attenuation of angiogenesis [23] and autophagy [24]. Our current data for the first time demonstrate that $\mathrm{XN}$ could kill cancer cells via induction of paraptosis. The activation of caspase in the HL-60 leukemia cells by XN treatment was examined, the activation of caspase 3 and the cleaved fragments of caspase- 3 were not detected, indicating that caspase activation is not involved in $\mathrm{XN}$-induced paraptosis of HL-60 leukemia cells. The results from the caspase inhibitors also verified that there is no involvement of caspase activation in $\mathrm{XN}$ treated HL-60 leukemia cells. Because $\mathrm{XN}$ treatment resulted in cytoplasmic vacuolation in the HL-60 leukemia cells, we determine whether autophagic flux was involved in the XN-treated HL-60 leukemia cells. The results demonstrated that XN treatment up-regulated the levels of LC3-II and p62 but did not alter Beclin-1 levels. The pretreatment of HL-60 leukemia cells with the inhibitor of autophagic flux did not observe the alterations in the numbers of viable cells. It indicated that autophagy was inhibited at the fusion of autophagosomes with lysosomes step and not involved in the $\mathrm{XN}$ induced cell death.

$\mathrm{XN}$ treatment induces swelling and fusion of the endoplasmic reticulum, and results in the formation of expanded endoplasmic reticulum structures. In terms of these interesting finding, the signaling pathways responsible for the dilation of the endoplasmic reticulum (ER) during XN-induced paraptosis of HL-60 leukemia cells were determined. The unfolded proteins accumulation can activate the intracellular signaling pathways that trigger the unfolded protein response and endoplasmic reticulum-associated degradation to prevent the cells from toxicity of unfolded and mal-folded proteins. In
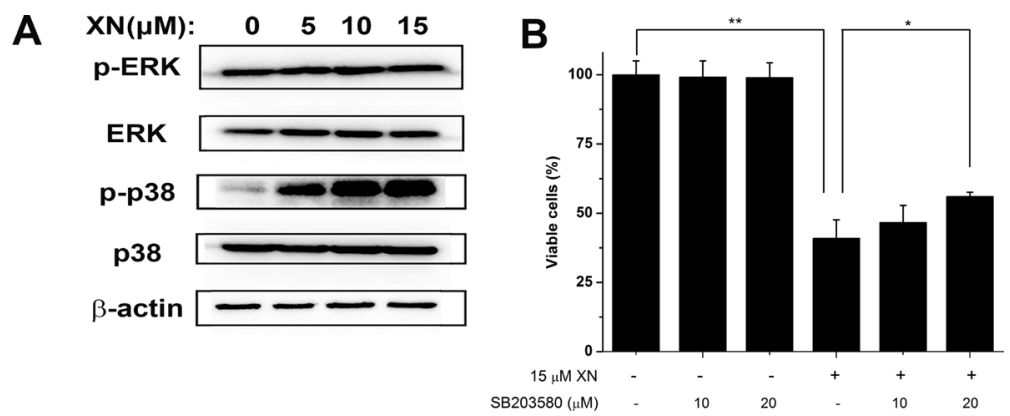

Figure 5: p38 mitogen activated protein kinase mediates XN-induced paraptosis. (A) The HL-60 leukemia cells were treated with $5 \mu \mathrm{M}, 10 \mu \mathrm{M}, 15 \mu \mathrm{M} \mathrm{XN}$ for $48 \mathrm{~h}$ and the total and relative phosphorylation levels of the mitogen activated protein kinase (MAPK) were determined by Western blot. (B) The cells were untreated or pretreated with the indicated specific p38 inhibitor (SB203580) at the indicated concentrations for $1 \mathrm{~h}$ and further treated with $15 \mu \mathrm{M} \mathrm{XN}$ for $48 \mathrm{~h}$. The cellular viability was assessed using trypan blue staining. All data are expressed as mean \pm S.D. from three independent experiments. ${ }^{*} P<0.05,{ }^{*} P<0.01$ vs. control group. 
this regard, we found that $\mathrm{XN}$ treatment significantly inhibited the proteasome activity and induced generation of unfolded proteins and the ER-stress markers such as transcription factor CHOP and Bip/Grp78 and thus may lead to cell death. Furthermore, the $\mathrm{CHX}$ pretreatment attenuated the $\mathrm{XN}$-induced vacuolation and paraptosis. The results suggest that a protein synthesis is required for $\mathrm{XN}$ treatment induced dilation of endoplasmic reticulum of HL-60 leukemia cells. When we examined the activity changes in the mitogen-activated protein kinases, we found that p38 but not ERK was activated. The pretreatment with only inhibitor of p38 but not ERK, the cell survival rate were significantly rescued. Therefore, p38 activation was shown to be critical for paraptosis induced by XN.

In conclusion, we have reported for the first time that $\mathrm{XN}$ treatment can induce paraptosis of HL-60 leukemia cells. The paraptosis is characterized by cytoplasmic vacuolation without caspase activation and autophagic flux. The dilatation of ER and the accumulation of unfolded proteins and ER stress marker proteins were also observed in XN-treated HL-60 leukemia cells. Moreover, p38 MAPK specific inhibitor significantly prevented XN-induced paraptosis indicating the involvement of $\mathrm{p} 38$ pathways in $\mathrm{XN}$-induced paratosis. Therefore, $\mathrm{XN}$ induced paraptosis could be a potential implication on cancer therapeutics.

\section{MATERIALS AND METHODS}

\section{Chemicals and antibodies}

Xanthohumol was obtained from Yumen Technology Development Limited Company (Gansu , China) with a purity $\geq 98 \%$ determined by HPLC. Xanthohumol stock solutions were prepared in dimethyl sulfoxide (DMSO) and diluted to the indicated concentrations before use. Trypan blue was purchased from Sigma-Aldrich (USA). The Cell Counting Kit-8 assay was obtained from Dojindo Laboratories (Japan). Caspase inhibitors Z-VADFMK was purchased from Medchemexpress (USA). Cycloheximide (CHX), SB203580 and 3-methyladenine (3-MA) were purchased from Selleck (USA). The Cyto$\mathrm{ID}^{\circledR}$ green dye autophagy detection kit was from Enzo Life Sciences (Switzerland). The Proteasome Activity Assay Kit was purchased from Abcam (England). The following antibodies were used: anti- $\beta$-actin, anti-caspase- 3 , antiCHOP, anti-p62 (Cell Signaling); anti-LC3B (SigmaAldrich); anti-Ubiquitin (Abcam); anti-phospho-ERK1/2, total ERK1/2, phospho-p38, and total p38 (Santa Cruz Biotechnologies); goat anti-rabbit IgG-HRP and goat antimouse IgG-HRP (Santa Cruz Biotechnologies).

\section{Cell culture and treatments}

HL-60 cell line (human promyelocytic leukemia cell line) and SH-SY5Y cell line (human dopaminergic neuroblastoma cells) were obtained from the Shanghai Cell
Bank. HL-60 leukemia cells was propagated in Iscove's modified Dulbecco's medium (IMDM) supplemented with $20 \%$ (v/v) fetal bovine serum, $2 \mathrm{mM} \mathrm{L}$-glutamine, $100 \mathrm{IU} / \mathrm{mL}$ penicillin and $100 \mu \mathrm{g} / \mathrm{mL}$ streptomycin at $37^{\circ} \mathrm{C}$ in air with $5 \% \mathrm{CO}_{2}$ in a humidified incubator. The cells were passaged twice a week and used in the exponential growth phase. To assess viability, the cells were seeded $\left(1 \times 10^{5}\right.$ cells $\left./ \mathrm{mL}\right)$ in flat-bottomed 6-well tissue culture plates and incubated with different concentrations of XN for $48 \mathrm{~h}$. SH-SY5Y cells were grown in Dulbecco's modified Eagle medium (DMEM) supplemented with 10\% fetal bovine serum, 2 $\mathrm{mM}$ L-glutamine, $100 \mathrm{IU} / \mathrm{mL}$ penicillin and $100 \mu \mathrm{g} / \mathrm{mL}$ streptomycin at $37^{\circ} \mathrm{C}$ in air with $5 \% \mathrm{CO}_{2}$ in a humidified incubator.

\section{CCK-8 assay}

Cell viability was estimated by the CCK- 8 assay. Approximately $10^{4}$ cells were seeded in 96-well plates with $100 \mu \mathrm{L}$ medium each well. After $24 \mathrm{~h}$ cultivation, different doses of $\mathrm{XN}$ were added. Each well was incubated with $10 \mu \mathrm{g}$ CCK-8 solution for $4 \mathrm{~h}$ away from light before measuring the absorbance at $450 \mathrm{~nm}$ by MultiMode Detection platform (Molecular Devices).

\section{Confocal microscopy}

To visualize autophagic vacuoles and monitor autophagic flux in HL-60 leukemia cells with or without $\mathrm{XN}$ treatment, confocal microscopy was used. HL-60 leukemia cells were treated with $15 \mu \mathrm{M}$ of $\mathrm{XN}$ for $48 \mathrm{~h}$, with cells treated with $50 \mathrm{nM}$ autophagy inducer rapamycin for $8 \mathrm{~h}$ as positive controls. Thereafter, cells were washed twice with culture medium and then treated with nuclear dye DAPI and autophagy detection kit Cyto$\mathrm{ID}^{\circledR}$ green dye at $37^{\circ} \mathrm{C}$ for $15 \mathrm{~min}$. Confocal images were acquired using a Zeiss LSM-700 confocal microscope equipped with Plan-Apo $63 \times 1.4$ NA oil-immersion objectives. Fluorescence intensity was quantitatively analyzed using ZEN 2010 software (Carl Zeiss). Images were edited with Photoshop (Adobe).

\section{Transmission electron microscopy}

After XN-treatment, cells were fixed in a fixative solution ( $2 \%$ formaldehyde and 2\% glutaraldehyde in $0.1 \mathrm{M}$ sodium cacodylate buffer, $\mathrm{pH} 7.4$ ) at $4^{\circ} \mathrm{C}$ overnight. Then the cells were washed with $0.1 \mathrm{M}$ sodium cacodylate buffer ( $\mathrm{pH} 7.4$ ) and post-fixed in $1 \% \mathrm{OsO}_{4}$ for $1 \mathrm{~h}$. Ultrathin sections were stained with uranyl acetate and lead citrate, and examined by transmission electron microscopy (JEM 1200 EX II, JEOL Ltd., Japan).

\section{Annexin V-FITC/PI assay}

Apoptosis was examined using Annexin V Apoptosis Detection Kit FITC (Affymetrix eBioscience, 
USA). The HL-60 leukemia cells were prepared according to the manufacuturer's instructions. Briefly, approximately $1 \times 10^{5}$ cells per experimental condition were harvested, washed with cold PBS twice, and resuspended with $200 \mu \mathrm{L}$ Binding buffer. Adding $5 \mu \mathrm{L}$ of fluorochromeconjugated Annexin V solution and $10 \mu \mathrm{L}$ PI solution, cells were incubated for $15 \mathrm{~min}$ at room temperature in the dark. Samples were analyzed by flow cytometry (BD). Data were analyzed using MODFIT software.

\section{Proteasome activity assay}

Proteasome activity was measured by proteasome activity assay kit (Abcam) using a multi-mode detection platform. Fluorescence was measured using a Multi-Mode Detection platform (Molecular Devices) in the presence/ absence of MG132 after $5 \mathrm{~min}$ at $37^{\circ} \mathrm{C}$ for $30 \mathrm{~min}$. The MG132-sensitive increase of fluorescence at 350/440 nm was considered as proteasomal activity.

\section{Western blotting analysis}

After XN-treatment, cells were lysed in RIPA buffer (Beyotime, Nanjing, China) and centrifuged at $14,000 \times \mathrm{g}$ for $20 \mathrm{~min}$. Protein samples were separated electrophoretically by SDS-PAGE and transferred onto a polyvinylidene difluoride membrane. The membrane was incubated with $5 \%$ non-fat milk in TBST (Tris-buffered saline tween 20) at room temperature for $1 \mathrm{~h}$. Washing with TBST, the membrane was incubated with primary antibody at $4^{\circ} \mathrm{C}$ overnight, and then incubated with horseradish peroxidas-conjugated secondary antibody at room temperature for 1 hour. The bound antibody was detected by chemiluminescence kit (Thermo scientific, USA) and immunoreactive protein bands were performed by densitometric analysis.

\section{Statistical analysis}

Data are presented as means \pm SEM from at least three independent experiments and evaluated by analysis of variance (ANOVA) followed by Student Newman-Keuls test. Values of $P<0.05$ were considered statistically significant. All analyses were performed using the SPSS version 19.0.

\section{Abbreviations}

AML: acute myeloid leukemia; Bip/GRP78: immunoglobulin heavy chain binding protein in pre-B cells; CHX: cycloheximide; CHOP: C/EBP homologous protein; GFP: green fluorescent protein; ER: endoplasmic reticulum; ERAD: ER- associated degradation; ERK: extracellular signal-regulated kinase; LC3: microtubule-associated protein 1 light chain 3; 3-MA: 3-methyladenine; MAPK: mitogen activated protein kinase; SQSTM1/p62: sequestosome 1; UPR: unfolded protein response; XN: Xanthohumol

\section{Authors' contributions}

Design and conduct of the study: Mi X, Wang C, Li J, Data collection and analysis: Mi X, Sun C, Chen X, Huo X, Zhang Y, Li G, Wang Z. Data interpretation: Mi X, Li G, Xu B, Wang C, Wang Z, Li J Manuscript writing: Mi X, Li J.

\section{ACKNOLEDGMENTS}

These studies were supported by the National Natural Science Foundation of China (21372190 and 31470426), the Taishan Scholar Program of Shandong Province (tshw201502046) and 2016 Yantai ShuangBai Scholar Program.

\section{CONFLICTS OF INTEREST}

The authors declare that they have no conflicts of interest.

\section{REFERENCES}

1. Okada H, Mak TW. Pathways of apoptotic and nonapoptotic death in tumour cells. Nat Rev Cancer. 2004; 4:592-603.

2. Longley DB, Johnston PG. Molecular mechanisms of drug resistance. J Pathol. 2005; 205:275-292.

3. Elmore S. Apoptosis: a review of programmed cell death. Toxicol Pathol. 2007; 35:495-516.

4. Shen S, Kepp O, Michaud M, Martins I, Minoux H, Metivier D, Maiuri MC, Kroemer RT, Kroemer G. Association and dissociation of autophagy, apoptosis and necrosis by systematic chemical study. Oncogene. 2011; 30:4544-4556.

5. Kar R, Singha PK, Venkatachalam MA, Saikumar P. A novel role for MAP1 LC3 in nonautophagic cytoplasmic vacuolation death of cancer cells. Oncogene. 2009; 28:2556-2568.

6. Kim SH, Kang JG, Kim CS, Ihm SH, Choi MG, Yoo HJ, Lee SJ. The hsp70 inhibitor VER155008 induces paraptosis requiring de novo protein synthesis in anaplastic thyroid carcinoma cells. Biochem Biophys Res Commun. 2014; 454:36-41.

7. Wasik AM, Almestrand S, Wang X, Hultenby $\mathrm{K}$, Dackland AL, Andersson P, Kimby E, Christensson B, Sander B. WIN55,212-2 induces cytoplasmic vacuolation in apoptosis-resistant MCL cells. Cell Death Dis. 2011; 2:e225.

8. Sugimori N, Espinoza JL, Trung LQ, Takami A, Kondo Y, An DT, Sasaki M, Wakayama T, Nakao S. Paraptosis cell death induction by the thiamine analog benfotiamine in leukemia cells. PLoS One. 2015; 10:e0120709.

9. Liu M, Hansen PE, Wang G, Qiu L, Dong J, Yin H, Qian Z, Yang M, Miao J. Pharmacological profile of xanthohumol, a prenylated flavonoid from hops (Humulus lupulus). Molecules. 2015; 20:754-779.

10. Yong WK, Ho YF, Malek SNA. Xanthohumol induces apoptosis and $\mathrm{S}$ phase cell cycle arrest in A549 non-small 
cell lung cancer cells. Pharmacogn Mag. 2015; 11:S275-283.

11. Slawinska-Brych A, Krol SK, Dmoszynska-Graniczka M, Zdzisinska B, Stepulak A, Gagos M. Xanthohumol inhibits cell cycle progression and proliferation of larynx cancer cells in vitro. Chem Biol Interact. 2015; 240:110-118.

12. Lee WJ, Chien MH, Chow JM, Chang JL, Wen YC, Lin YW, Cheng CW, Lai GM, Hsiao M, Lee LM. Nonautophagic cytoplasmic vacuolation death induction in human PC-3M prostate cancer by curcumin through reactive oxygen species -mediated endoplasmic reticulum stress. Sci Rep. $2015 ; 5: 10420$.

13. Wang WB, Feng LX, Yue QX, Wu WY, Guan SH, Jiang BH, Yang M, Liu X, Guo DA. Paraptosis accompanied by autophagy and apoptosis was induced by celastrol, a natural compound with influence on proteasome, ER stress and Hsp90. J Cell Physiol. 2012; 227:2196-2206.

14. Mi JY, Kim EH, Kwon TK, Sun AP, Choi KS. Simultaneous mitochondrial $\mathrm{Ca} 2+$ overload and proteasomal inhibition are responsible for the induction of paraptosis in malignant breast cancer cells. Cancer Letters. 2012; 324:197-209.

15. Lee D, Kim IY, Saha S, Choi KS. Paraptosis in the anticancer arsenal of natural products. Pharmacol Ther. 2016; 162:120-133.

16. Salvesen GS, Dixit VM. Caspases:Intracellular Signaling by Proteolysis. Cell. 1997; 91:443-446.

17. Sabina S, I DB, Bredesen DE. An alternative, noapoptotic form of programmed cell death. Proc Natl Acad Sci USA. 2000; 97:14376-14381.

18. Dong HS, Kim MK, Kim HS, Chung HH, Yong SS. Unfolded protein response to autophagy as a promising druggable target for anticancer therapy. Annals of the New York Academy of Sciences. 2012; 1271:20-32.

19. Martinon F. Targeting endoplasmic reticulum signaling pathways in cancer. Acta Oncologica. 2012; 51:822-830.

20. Dietz BM, Kang YH, Liu G, Eggler AL, Yao P, Chadwick LR, Pauli GF, Farnsworth NR, Mesecar AD and van Breemen RB. Xanthohumol isolated from Humulus lupulus Inhibits menadione-induced DNA damage through induction of quinone reductase. Chemical Research in Toxicology. 2005; 18:1296-1305.

21. Kunnimalaiyaan S, Sokolowski KM, Balamurugan M, Gamblin TC, Kunnimalaiyaan M. Xanthohumol Inhibits Notch Signaling and Induces Apoptosis in Hepatocellular Carcinoma. Plos One. 2015; 10:e0127464.

22. Jongthawin J, Techasen A, Loilome W, Yongvanit P, Namwat N. Anti-inflammatory agents suppress the prostaglandin E2 production and migration ability of cholangiocarcinoma cell lines. Asian Pacific Journal of Cancer Prevention. 2012; 13:47-51.

23. Albini A, Dell'Eva R, Vené R, Ferrari N, Buhler DR, Noonan DM, Fassina G. Mechanisms of the antiangiogenic activity by the hop flavonoid xanthohumol: NF- $\kappa \mathrm{B}$ and Akt as targets. FASEB Journal. 2006; 20:527-529.

24. Sasazawa Y, Kanagaki S, Tashiro E, Nogawa T, Muroi M, Kondoh Y, Osada H, Imoto M. Xanthohumol Impairs Autophagosome Maturation through Direct Inhibition of Valosin-Containing Protein. Acs Chemical Biology. 2012; 7:892-900. 